\title{
Perbandingan Metode Evaporasi Potensial Di Badan Meteorologi Klimatologi Dan Geofisika Sawahan Kabupaten Nganjuk, Jawa Timur
}

\author{
Comparison of Potential Evaporation Methods in the Meteorology, \\ Climatology and Geophysics Agency of Sawahan, Nganjuk Regency, East \\ Java
}

Ery Suhartanto $^{\left.1^{*}\right)}$, Lily Montarcih Limantara ${ }^{1}$, Hana Arum Rossy Tamaya ${ }^{1}$

${ }^{1}$ Jurusan Teknik Pengairan, Fakultas Teknik, Universitas Brawijaya, Malang, Indonesia

Article info:

Kata kunci:

christiansen, evaporasi, hamon, regresi linier berganda, turc.

Keywords:

christiansen, evaporation, hamon, multiple linear regression, turc.

Article history:

Received: 21-08-2019

Accepted: 19-02-2020

*)Koresponden email: erysuhartanto@ub.ac.id

\section{Abstrak}

Penelitian ini bertujuan untuk mendapatkan model empiris yang sesuai untuk estimasi evaporasi pada wilayah Nganjuk. Studi ini dilakukan di stasiun meteorologi Sawahan yang digunakan untuk menghitung evaporasi dengan menggunakan metode BlaneyCriddle, metode Penman, metode Radiasi, metode Turc, metode Hamon, metode Christiansen serta modifikasi menggunakan metode Regresi Linier Berganda. Hasil dari masing-masing metode dibandingkan dengan hasil yang lain dan dilakukan uji validasi menggunakan kesalahan relatif $(K r)$, uji Efisiensi Nash-Sutcliffe (ENS) dan Root Mean Square Error (RMSE). Berdasarkan hasil yang diperhitungkan dapat disimpulkan bahwa metode yang sesuai adalah metode regresi linier berganda dengan hasil uji validasi yang meliputi nilai kesalahan relatif $(K r)$ adalah 1.15 , nilai uji Efisiensi Nash Sutcliffe (ENS) adalah 0.70 dan nilai Root Mean Square Error (RMSE) adalah 0.18 .

\section{Abstract}

The research aims to obtain an appropriate empirical model for a reasonable estimation of reference evaporation for the Nganjuk region. In this research, the observations were recorded at Sawahan meteorological station are used to calculate the evaporation with the methods of Blaney-Criddle, Penman method, Radiation method, Turc method, Hamon method, Christiansen method, and multiple linear regression method. The results of each method compared with the results of the other and the validation tests used relative error $(K r)$, Nash-Sutcliffe Efficiency (ENS), and Root Mean Square Error (RMSE). Based on the calculated results it concluded that the appropriate method was multiple linear regression with validation test as follows: rate of relative error $(\mathrm{Kr})$ is 1.15, rate of Nash Sutcliffe Efficiency (ENS) is 0.70 and rate of Root Mean Square Error (RMSE) is 0.18 .

Kutipan: Suhartanto, E., Montarcih Limantara, L., \& Arum Rossy Tamaya, H. (2020). Perbandingan Metode Evaporasi Potensial Di Badan Meteorologi Klimatologi Dan Geofisika Sawahan Kabupaten Nganjuk, Jawa Timur. Jurnal Teknik Pengairan. https://doi.org/10.21776/ub.pengairan.2020.011.01.01

\section{Pendahuluan}

Air merupakan salah satu sumber alam yang dapat diperbaharui serta akan mempunyai daya regenerasi yang selalu berada di dalam sirkulasinya dari suatu siklus. Siklus tersebut umumnya 
disebut dengan siklus hidrologi (Soewarno 2015b). Dari siklus hidrologi diketahui bahwa curah hujan yang terakumulasi di permukaan bumi sebagian air tersebut akan kembali ke atmosfer sebagai uap. Permukaan bumi yang mengalami penguapan secara kontinyu akan terjadi proses perubahan molekul air menjadi uap air atau sebaliknya. Banyaknya air yang menguap itu merupakan data yang penting dalam mempelajari hidrologi suatu daerah pengaliran sungai (Bartholomeus et al. 2015; Van Osnabrugge, Uijlenhoet, and Weerts 2019).

Hidrologi adalah ilmu yang mempelajari masalah keberadaan air di bumi dan hidrologi itu sendiri memberikan alternatif bagi pengembangan sumber daya air bagi keperluan air baku. pertanian. industri dan kelistrikan (Hadisusanto 2011). Kondisi meteorologi setiap saat selalu berubah-ubah karena pengaruh kondisi permukaan dan kondisi lingkungan sehingga diperlukan pengamatan yang sangat teliti. Pengetahuan mengenai proses penguapan merupakan faktor yang sangat penting untuk ahli hidrologi dan ahli meteorologi karena berguna untuk mengetahui apakah terjadi penurunan atau kenaikan laju evaporasi terkait dengan perubahan iklim (Barella-Ortiz et al. 2013; Maes et al. 2018; Matsoukas et al. 2011; Suhartanto and Haribowo 2011). Evaporasi merupakan proses fisis yang merubah bentuk larutan atau cairan menjadi bentuk gas atau uap. Istilah ini juga diartikan sebagai jumlah uap air yang diuapkan dari satu permukaan tanah ataupun air (Hadisusanto 2011; McMahon et al. 2013).

Studi ini dilakukan di Sawahan Kabupaten Nganjuk. Kabupaten Nganjuk terletak antara $111^{\circ} 5^{\prime}$ sampai dengan $112^{\circ} 13^{\prime}$ BT dan $7^{\circ} 20^{\prime}$ sampai dengan $7^{\circ} 50^{\prime}$ LS serta luas DAS Widas yang memiliki luas $\pm 1,502 \mathrm{~km}^{2}$. Luas Kabupaten Nganjuk sekitar $122.433 \mathrm{~km}^{2}$ atau setara $122.433 \mathrm{Ha}$. Curah hujan di Kabupaten Nganjuk tidak jauh berbeda dengan wilayah lainnya di Provinsi Jawa Timur. Pada bulan Juni sampai dengan September/Oktober di Kabupaten Nganjuk akan mengalami musim kemarau dan bulan Nopember/Desember sampai bulan Mei akan mengalami musim hujan. Evaporasi sangat penting sebagai faktor kehilangan air dalam perencanaan pengembangan sumber daya air. Untuk itu perlu dipilih beberapa metode yang cocok berdasarkan data meteorologi yang tersedia.

Untuk menghitung nilai evaporasi dalam studi ini menggunakan metode Blaney-Criddle, metode Penman, metode Radiasi, metode Turc, metode Hamon, metode Christiansen dan metode Regresi Linier Berganda. Dari pemakaian beberapa metode yang akan digunakan bisa didapatkan perbandingan antara ketujuh metode tersebut dan nilai evaporasi potensial yang dihasilkan dapat diketahui. Penggunaan berbagai metode yang dilakukan menyebabkan perbedaan nilai pada suatu daerah pengamatan. Dalam studi ini akan membandingkan metode evaporasi potensial tersebut dengan menggunakan tujuh metode sehingga didapatkan metode yang sesuai untuk daerah studi.

\section{Bahan dan Metode}

Studi ini dilakukan di Stasiun Geofisika Sawahan Kabupaten Nganjuk. Jawa Timur (Gambar 1). Data yang dipergunakan dalam studi ini merupakan data iklim yang terdiri dari data suhu udara. data kelembaban udara, data curah hujan, data lama penyinaran matahari, data kecepatan angin dan data hasil pengamatan pan evaporasi di Stasiun Geofisika Sawahan. Pada studi ini, data diperoleh dari stasiun geofisika Sawahan Nganjuk. Data yang akan digunakan adalah data selama 10 tahun yang merupakan data dari tahun 2007 sampai 2016.

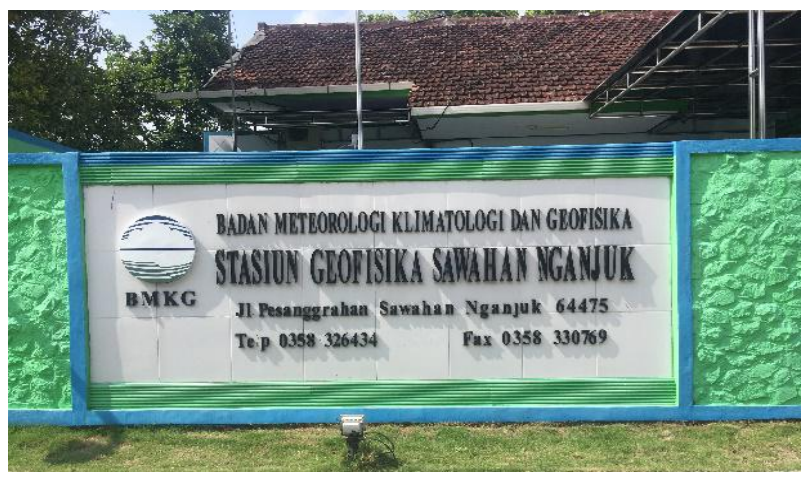

Gambar 1. Stasiun Geofisika Sawahan Nganjuk 
Metode evaporasi yang digunakan dalam studi ini adalah:

a) Metode Blaney-Criddle $(B C)$

Metode Blaney-Criddle digunakan dalam memperkirakan evaporasi potensial berdasarkan data suhu (Limantara 2010). Rumus yang digunakan dapat dijelaskan sebagai berikut:

$$
\begin{gathered}
E T_{0}=c . E T_{0} * \\
E T 0^{*}=P(0.46 t+8.13)
\end{gathered}
$$

dengan $E T_{0}=$ evaporasi potensial $(\mathrm{mm} / \mathrm{hari}), \mathrm{c}=$ angka koreksi, $E T_{0} *=$ evaporasi sebelum dikoreksi $(\mathrm{mm} / \mathrm{hari}), P=$ prosentase rata-rata jam siang $(\%)$, dan $t=$ temperatur $\left({ }^{\circ} \mathrm{C}\right)$

b) Metode Radiasi $(R)$

Metode Radiasi digunakan dalam memperkirakan nilai evaporasi potensial dengan menggunakan data suhu dan data lama penyinaran matahari (Limantara 2010). Perhitungan metode Radiasi ditunjukkan dengan persamaan:

$$
\begin{aligned}
& E T_{0}{ }^{*}=w . R s \\
& E T_{0}=c . E T^{*}
\end{aligned}
$$

dengan $w=$ faktor pengaruh suhu dan elevasi ketinggian daerah, $R s=$ radiasi gelombang pendek yang diterima bumi ( $\mathrm{mm} /$ hari), dan $c=$ angka koreksi.

c) Metode Penmann $(P)$

Metode Penmann digunakan dalam memperkirakan evaporasi potensial berdasarkan data suhu, kecepatan angin, lama penyinaran matahari dan kelembaban udara (Limantara 2010). Persamaan berikut dapat digunakan untuk mendapatkan evaporasi metode Penmann:

$$
\begin{gathered}
E T_{0}=c \cdot E T_{0} * \\
E T_{0} *=w(0.75 R s-R n 1)+(1-w) f(u)(\varepsilon r-\varepsilon d)
\end{gathered}
$$

dengan $E T_{0}=$ evaporasi potensial $(\mathrm{mm} /$ hari),$c=$ angka koreksi, $w=$ faktor pengaruh suhu dan elevasi ketinggian daerah, $R s=$ radiasi gelombang pendek yang diterima bumi $(\mathrm{mm} / \mathrm{hari}), f(u)=$ fungsi kecepatan angin pada ketinggian, $R n 1$ = radiasi bersih gelombang panjang $(\mathrm{mm} / \mathrm{hari})$, dan $\varepsilon \gamma-\varepsilon d=$ perbedaan tekanan uap jenuh dengan tekanan uap sebenarnya.

d) Metode Turc

Metode Turc digunakan dalam memperkirakan evaporasi potensial berdasarkan data suhu dan data curah hujan (Hadisusanto 2011). Rumus metode Turch ditunjukkan pada persamaan berikut:

$$
E=\frac{\mathrm{P}}{0,90+\frac{\mathrm{P}}{\mathrm{L}_{\mathrm{T}}{ }^{2}}}
$$

dengan $E=$ evaporasi rerata tahunan ( $\mathrm{mm} /$ hari), $P=$ hujan rerata tahunan $(\mathrm{mm}), t=$ suhu udara rerata tahunan $\left({ }^{\circ} \mathrm{C}\right), L_{T}=$ evaporative demand of the atmosphere.

e) Metode Hamon

Metode Hamon digunakan dalam memperkirakan evaporasi potensial berdasarkan data suhu dan data kelembaban udara. Perhitungan evaporasi metode Hamon ditunjukkan sebagai berikut:

$$
E=0,55\left(\frac{\mathrm{D}}{12}\right)^{2} \frac{\mathrm{SVD}}{100}(25,4)
$$

dengan $E$ = evaporasi potensial (mm/hari), $D=$ jam siang hari, dan $S V D=$ kelembaban relatif.

f) Metode Christiansen

Metode Christiansen digunakan dalam memperkirakan evaporasi potensial berdasarkan data suhu, data lama penyinaran matahari, data kecepatan angin dan data kelembaban udara serta elevasi daerah studi. Perhitungan evaporasi metode Christiansen dapat dijelaskan sebagai berikut:

$$
E=0.459 R_{a} C_{t} C_{w} C_{s} C_{h} C_{e}
$$

dengan $R_{a}=$ radiasi matahari atas atmosfer, $C_{t}=$ koefisien suhu, $C_{w}=$ koefisien angina, $C_{s}=$ koefisien sinar matahari, $C_{h}=$ koefisien kelembaban, dan $C_{e}=$ koefisien elevasi. 
g) Metode Regresi Linier Berganda

Metode Regresi Linier Berganda digunakan dalam memperkirakan evaporasi potensial menggunakan data iklim, yaitu data suhu, lama penyinaran matahari, kecepatan angina, kelembaban udara, dan curah hujan terhadap data pan yang telah diukur pada daerah studi (Soewarno 2015a). Rumus umum persamaan regresi linier disajikan sebagai berikut:

$$
\hat{Y}=A_{0}+A_{1} X_{1}+\ldots+A_{i} X_{i}+\ldots A_{m-1} X_{m-1}
$$

dengan $A_{0}=$ titik potong dan $A_{i}=$ koefisien regresi berganda dari variabel $Y$ terhadap $X$.

Metode ini bertujuan untuk mengetahui hubungan dua variabel hidrologi atau lebih yang dinyatakan dalam rumus matematik sehingga merupakan suatu model yang mampu digunakan dalam analisis hidrologi.

Setelah didapatkan metode yang sesuai untuk daerah studi maka akan dilakukan uji validasi menggunakan uji sebagai berikut:

a. Kesalahan Relatif $(\mathrm{Kr})$

Kesalahan relatif $(\mathrm{Kr})$ adalah persentase dari selisih besaran parameter data model atau peramalan dengan besaran parameter data aktual dibagi dengan besaran parameter data aktual (Fathoni, Dermawan, and Suhartanto 2016). Nilai kesalahan relatif dapat dihitung dengan persamaan berikut:

$$
K r=\left[\frac{X_{a}-X_{b}}{X_{n}}\right] \times 100 \%
$$

dengan $\mathrm{Kr}=$ kesalahan relatif (\%), $X a=$ evaporasi pengukuran ( $\mathrm{mm} / \mathrm{hari})$, dan $X b=$ evaporasi empiris (mm/hari)

b. Uji Efisiensi Nash-Sutcliffe (ENS)

Uji Efisiensi Nash-Sutcliffe (ENS) adalah uji yang akan digunakan untuk mengetahui kemiripan data dari hasil analisa dengan data. Nilai Nash-Sutcliffe (ENS) diperoleh dengan menggunakan persamaan berikut (Suhartanto, Cahya, and Maknun 2019):

$$
E N S=1-\frac{\sum_{i=1}^{\mathrm{n}}\left(\mathrm{O}_{\mathrm{i}}-\mathrm{p}_{\mathrm{i}}\right)^{2}}{\sum_{\mathrm{i}=1}^{\mathrm{n}}\left(\mathrm{O}_{\mathrm{i}}-\overline{\mathrm{O}}\right)^{2}}
$$

dengan $P_{i}=$ nilai perhitungan, $O_{i}=$ nilai data pengukuran, dan $\overline{0}=$ nilai rata-rata hasil pengukuran

c. Root Mean Square Error

Root Mean Square Error (RMSE) adalah perbandingan yang digunakan untuk membandingkan antara nilai yang didapatkan dari hasil analisa menggunakan tujuh metode dan nilai yang sebenarnya diamati dari lokasi studi yang sedang dimodelkan (Suryaningtyas, Suhartanto, and Rispiningtati 2020). Standar nilai hasil perhitungan Root Mean Square Error (RMSE) yaitu kisaran $0-1$.

$$
R M S E=\sqrt{\frac{\sum_{\mathrm{i}=1}^{\mathrm{n}}\left(\mathrm{y}_{\mathrm{i}}-\widehat{y}_{\mathrm{i}}\right)^{2}}{\mathrm{n}}}
$$

dengan $N=$ jumlah data, $Y i=$ sampel data pengukuran, dan $\hat{Y} i=$ sampel data hasil analisa.

\section{Hasil dan Pembahasan}

\subsection{Metode Evaporasi}

Berdasarkan nilai evaporasi yang ditunjukkan pada Tabel 1, maka dapat diketahui bahwa:

a. Metode Blaney-Criddle. Nilai evaporasi potensial maksimum yang dihasilkan adalah 4.79 $\mathrm{mm} /$ hari pada tahun 2016 dan nilai evaporasi potensial minimum adalah $4.47 \mathrm{~mm} / \mathrm{hari}$ pada tahun 2008. 
Tabel 1. Rekapitulasi Nilai Evaporasi

\begin{tabular}{cccccccc}
\hline $\begin{array}{c}\text { Evaporasi } \\
\text { Panci } \\
(\mathrm{mm} / \text { hari })\end{array}$ & $B C$ & $R$ & $P$ & Turc & Hamon & Christiansen & Regresi \\
\cline { 2 - 8 } & 4.51 & 4.71 & 5.29 & 9.11 & 7.37 & 10.57 & 4.67 \\
\hline 4.84 & 4.47 & 4.55 & 5.33 & 12.42 & 7.37 & 10.25 & 4.41 \\
\hline 4.23 & 4.55 & 4.74 & 5.76 & 7.57 & 7.18 & 10.90 & 4.66 \\
\hline 4.70 & 4.59 & 4.37 & 4.71 & 16.62 & 7.99 & 9.12 & 4.86 \\
\hline 4.92 & 4.78 & 5.41 & 6.09 & 9.76 & 7.72 & 11.53 & 5.16 \\
\hline 5.26 & 4.78 & 5.26 & 6.05 & 8.00 & 10.67 & 11.87 & 5.32 \\
\hline 5.11 & 4.75 & 5.35 & 5.26 & 11.70 & 11.51 & 11.22 & 5.46 \\
\hline 5.04 & 4.55 & 4.93 & 4.71 & 14.74 & 12.20 & 9.38 & 4.66 \\
\hline 4.50 & 4.56 & 5.17 & 4.84 & 12.48 & 12.07 & 9.90 & 4.51 \\
\hline 4.54 & 4.79 & 5.00 & 5.00 & 19.45 & 12.33 & 9.66 & 5.23 \\
\hline 5.26 & & & & & & &
\end{tabular}

b. Metode Radiasi. Nilai evaporasi potensial maksimum yang dihasilkan adalah $5.41 \mathrm{~mm} / \mathrm{hari}$ tahun 2011 dan nilai evaporasi potensial minimum adalah $4.37 \mathrm{~mm} /$ hari pada tahun 2010 .

c. Metode Penman. Nilai evaporasi potensial maksimum yang dihasilkan adalah $6.09 \mathrm{~mm} / \mathrm{hari}$ tahun 2011 dan nilai evaporasi potensial minimum $4.71 \mathrm{~mm} /$ hari pada tahun 2010 .

d. Metode Turc. Nilai evaporasi potensial maksimum yang dihasilkan adalah $19.45 \mathrm{~mm} / \mathrm{hari}$ tahun 2016 dan nilai evaporasi potensial minimum $7.57 \mathrm{~mm} /$ hari pada tahun 2007 .

e. Metode Hamon. Nilai evaporasi potensial maksimum yang dihasilkan adalah $12.33 \mathrm{~mm} / \mathrm{hari}$ tahun 2016 dan nilai evaporasi potensial minimum $7.18 \mathrm{~mm} /$ hari pada tahun 2009 .

f. Metode Christiansen. Nilai evaporasi potensial maksimum yang dihasilkan adalah 11.87 $\mathrm{mm} /$ hari pada tahun 2012 dan nilai evaporasi potensial minimum $9.12 \mathrm{~mm} /$ hari pada tahun 2010.

g. Metode Regresi Linier Berganda. Nilai evaporasi potensial maksimum sebesar $5.46 \mathrm{~mm} / \mathrm{hari}$ pada tahun 2013 dan nilai evaporasi potensial minimum sebesar $4.41 \mathrm{~mm} / \mathrm{hari}$ pada tahun 2008.

Dengan demikian. dapat diketahui bahwa nilai evaporasi rerata tahunan terkecil ditunjukkan oleh metode Radiasi $(R)$ dengan nilai $4.37 \mathrm{~mm} / \mathrm{hari}$.

\subsection{Uji Validasi}

- Kesalahan Relatif $(\mathrm{Kr})$

Tabel 2. Rekapitulasi kesalahan relatif $(K r)$

\begin{tabular}{cc}
\hline Metode evaporasi & Nilai $K r$ \\
\hline Blaney Criddle $(B C)$ & 3.98 \\
\hline Radiasi $(R)$ & 2.53 \\
\hline Penman $(P)$ & 9.85 \\
\hline Turc & 152.71 \\
\hline Hamon & 99.68 \\
\hline Christiansen & 116.20 \\
\hline Linier Berganda & 1.15 \\
\hline
\end{tabular}

Dengan melihat hasil yang ditunjukkan pada Tabel 2, maka dapat disimpulkan bahwa nilai kesalahan relatif $(\mathrm{Kr})$ yang terkecil dan sesuai untuk daerah studi adalah metode Regresi Linier Berganda dengan nilai 1.15 .

- Uji Efisiensi Nash-Sutcliffe (ENS)

Hasil rekapitulasi pengujian validasi masing-masing metode empiris dengan menggunakan Efisiensi Nash-Sutclife (ENS) disajikan pada Tabel 3. 
Tabel 3. Rekapitulasi Uji Efisiensi Nash-Sutcliffe (ENS)

\begin{tabular}{cc}
\hline Metode & ENS \\
\hline Blaney Criddle $(B C)$ & 0.12 \\
\hline Radiasi $(R)$ & -0.14 \\
\hline Penman $(P)$ & -3.15 \\
\hline Turc & -633.14 \\
\hline Hamon & -259.78 \\
\hline Christiansen & -300.81 \\
\hline Linier Berganda & 0.7 \\
\hline
\end{tabular}

Dengan mengacu hasil yang ditampilkan pada Tabel 3, maka dapat disimpulkan bahwa uji Efisiensi Nash-Sutcliffe (ENS) yang paling sesuai untuk daerah studi dan mendekati nilai 1 adalah metode Regresi Linier Berganda dengan nilai 0.7.

\section{- Root Mean Square Error (RMSE)}

Tabel 4 menunjukkan hasil rekapitulasi pengujian validasi metode empiris dengan menggunakan analisis Root Root Mean Square Error (RMSE).

Tabel 4. Rekapitulasi Root Mean Square Error (RMSE)

\begin{tabular}{cc}
\hline Metode & $R M S E$ \\
\hline Blaney Criddle $(B C)$ & 0.31 \\
\hline Radiasi $(R)$ & 0.35 \\
\hline Penman $(P)$ & 0.66 \\
\hline Turc & 8.20 \\
\hline Hamon & 5.26 \\
\hline Christiansen & 5.66 \\
\hline Linier Berganda & 0.18 \\
\hline
\end{tabular}

Dari Tabel 4 dapat diketahui bahwa dengan melakukan pengujian Root Mean Square Error (RMSE) dapat disimpulkan bahwa hasil analisis dengan error terkecil adalah metode Regresi Linier Berganda dengan nilai RMSE sebesar 0.18. Berdasarkan hasil pengujian validasi masing-masing metode empiris evaporasi yang telah dilakukan, maka dapat disimpulkan bahwa metode Regresi Linier Berganda merupakan metode yang paling sesuai untuk mengestimasi nilai evaporasi pada lokasi studi dengan tingkat keandalan yang baik.

\section{Kesimpulan}

Berdasarkan hasil analisis perbandingan nilai evaporasi dari metode empiris dengan evaporasi pengukuran dari panci evaporasi, maka dapat diketahui bahwa nilai perkiraan evaporasi yang dihasilkan dari metode Regresi Linier Berganda menunjukkan nilai yang paling sesuai dibandingkan dengan metode empiris lainnya. Hasil persamaan Regresi Linier Berganda yang diperoleh $E=-3.296+0.352 t+0.490 R h-0.61 P-0.285 n-0.325 v$ dengan $E$ adalah evaporasi perkiraan $(\mathrm{mm} / \mathrm{hari}), t$ adalah suhu udara $\left({ }^{\circ} \mathrm{C}\right), R h$ adalah kelembaban udara $(\%), P$ adalah curah hujan (mm), $n$ adalah lama penyinaran (jam), dan $v$ adalah kecepatan angin (m/detik). Hasil uji validasi yang dilakukan terhadap nilai evaporasi perkiraan dari metode Regresi Linier Berganda menunjukkan nilai kesalahan relatif $(K r)$ 1.15, nilai Efisiensi Nash-Sutcliffe (ENS) sebesar 0.7, dan nilai Root Mean Square Error (RMSE) sebesar 0.18. Dengan demikian. dari hasil studi ini yang telah dilakukan dapat disimpulkan bahwa metode Regresi Linier Berganda merupakan metode yang paling sesuai untuk mengestimasi nilai evaporasi pada lokasi studi dengan tingkat keandalan yang baik. 


\section{Daftar Pustaka}

Barella-Ortiz, A., J. Polcher, A. Tuzet, and K. Laval. 2013. "Potential Evaporation Estimation through an Unstressed Surface-Energy Balance and Its Sensitivity to Climate Change." Hydrology and Earth System Sciences 17(11): 4625-39.

Bartholomeus, R. P., J. H. Stagge, L. M. Tallaksen, and J. P.M. Witte. 2015. "Sensitivity of Potential Evaporation Estimates to 100 Years of Climate Variability." Hydrology and Earth System Sciences 19(2): 997-1014.

Fathoni, Syarief, Very Dermawan, and Ery Suhartanto. 2016. “Analisis Efektivitas Kerapatan Jaringan Pos Stasiun Hujan Di DAS Kedungsoko Dengan Menggunakan Jaringan Saraf Tiruan (Artificial Neural Network)." Jurnal Teknik Pengairan 7(1): 129-38.

Hadisusanto, Nugroho. 2011. Aplikasi Hidrologi. Edisi 1. Malang: Jogja Mediautama.

Limantara, Lily Montarcih. 2010. Hidrologi Praktis. Bandung: Lubuk Agung.

Maes, Wouter H., Pierre Gentine, Niko E. C. Verhoest, and Diego G. Miralles. 2018. "Potential Evaporation at Eddy-Covariance Sites across the Globe." Hydrology and Earth System Sciences Discussions (i): 1-38.

Matsoukas, C. et al. 2011. "Potential Evaporation Trends over Land between 1983-2008: Driven by Radiative Fluxes or Vapour-Pressure Deficit?” Atmospheric Chemistry and Physics 11(15): 7601-16.

McMahon, T. A. et al. 2013. "Estimating Actual, Potential, Reference Crop and Pan Evaporation Using Standard Meteorological Data: A Pragmatic Synthesis." Hydrology and Earth System Sciences 17(4): 1331-63.

Van Osnabrugge, Bart, Remko Uijlenhoet, and Albrecht Weerts. 2019. "Contribution of Potential Evaporation Forecasts to 10-Day Streamflow Forecast Skill for the Rhine River." Hydrology and Earth System Sciences 23(3): 1453-67.

Soewarno. 2015a. Analisis Data Hidrologi : Menggunakan Metode Statistika Dan Stokastik: Seri Hidrologi. Yogyakarta: Graha Ilmu.

_. 2015b. Klimatologi : Pengukuran Dan Pengolahan Data Curah Hujan, Contoh Aplikasi Hidrologi Dalam Pengelolaan Sumber Daya Air. Yogyakarta: Graha Ilmu.

Suhartanto, Ery, Evi Nur Cahya, and Lu'luil Maknun. 2019. “Analisa Limpasan Berdasarkan Curah Hujan Menggunakan Model Artificial Neural Network (ANN) Di Sub DAS Brantas Hulu." Jurnal Teknik Pengairan.

Suhartanto, Ery, and Riyanto Haribowo. 2011. "Application Of Kagan-Rodda Method For Rain Station Density In Barito Basin Area Of South Kalimantan, Indonesia." Journal of Applied Technology in Environmental Sanitation 1(4): 329-34.

Suryaningtyas, Lufi, Ery Suhartanto, and Rispiningtati. 2020. "Hydrological Analysis of TRMM (Tropical Rainfall Measuring Mission) Data in Lesti Sub Watershed." Civil and Environmental Science 003(01): 018-030. 